\title{
Secondary deterioration in patients with normal pressure hydrocephalus after ventriculoperitoneal shunt placement: a proposed algorithm of treatment
}

\author{
Pawel Gutowski ${ }^{*}$, Sergej Rot ${ }^{1}$, Michael Fritsch², Ullrich Meier ${ }^{1}$, Leonie Gölz ${ }^{3}$ and Johannes Lemcke ${ }^{1}$
}

\begin{abstract}
Background: After ventriculoperitoneal shunt surgery for idiopathic normal pressure hydrocephalus (iNPH) with adjustable gravitational valves, a certain proportion of patients develop secondary clinical worsening after initial improvement of clinical symptoms. The aim of this study was to analyze this group of patients with secondary deterioration and to evaluate the performed shunt management.
\end{abstract}

Methods: For this investigation, we retrospectively reviewed our NPH registry for patients included between 1999 and 2013 with a decrease by a minimum of two points in the Kiefer score in the first year of follow up and an increase of two points in the Kiefer score between the second and the fifth year after shunt surgery (secondary deterioration). Then, we analyzed the patient's shunt management (adapting the valve pressure setting, shuntography, valve replacement, catheter replacement, implant an adjustable gravitational unit). Additionally, we searched for risk factors for secondary deterioration.

Results: Out of $259 \mathrm{iNPH}$ patients, 53 (20\%) patients showed secondary deterioration on an average of 2.7 (2-4 years) years after shunt surgery. Fourteen (26\%) patients with secondary deterioration improved after shunt or valve management and 58\% remained without clinical benefit after management. We had a drop-out rate of $15 \%$ due to incomplete datasets. Our shunt management reduced the rate of secondary deterioration from 20 to $15 \%$. On the basis of our findings, we developed an algorithm for shunt management. Risk factors for secondary deterioration are the age of the patient at the time of shunting, newly diagnosed neurodegenerative diseases, and overdrainage requiring adjusting the valve to higher-pressure levels.

Conclusion: Twenty percent of patients with iNPH were at risk for secondary clinical worsening about 3 years after shunt surgery. About one-fourth of these patients benefited for additional years from pressure level management and/or shunt valve revision. Our findings underline the need for long-term follow-ups and intensive shunt management to achieve a favorable long-term outcome for patients with iNPH and VPS.

Keywords: NPH, Non-responder, Deterioration, Shunt failure, Neurodegenerative disease

*Correspondence: Pawel.Gutowski@ukb.de

1 Department of Neurosurgery, Unfallkrankenhaus Berlin, Warener Straße 7, 12683 Berlin, Germany

Full list of author information is available at the end of the article

\section{Background}

In 1965, Hakim and Adams [1] first described normal pressure hydrocephalus (NPH) which is characterized by a triad of symptoms with gait instability, urinary incontinence, and dementia. The incidence of iNPH in Germany is 1.08 per 100,000 [2]. Other studies reported an

c) The Author(s) 2020. This article is licensed under a Creative Commons Attribution 4.0 International License, which permits use, sharing, adaptation, distribution and reproduction in any medium or format, as long as you give appropriate credit to the original author(s) and the source, provide a link to the Creative Commons licence, and indicate if changes were made. The images or other third party material in this article are included in the article's Creative Commons licence, unless indicated otherwise in a credit line to the material. If material is not included in the article's Creative Commons licence and your intended use is not permitted by statutory regulation or exceeds the permitted use, you will need to obtain permission directly from the copyright holder. To view a copy of this licence, visit http://creativeco mmons.org/licenses/by/4.0/. The Creative Commons Public Domain Dedication waiver (http://creativecommons.org/publicdomain/ zero/1.0/) applies to the data made available in this article, unless otherwise stated in a credit line to the data. 
incidence of 1.19 to 5.5 per $100,000[3,4]$. The prevalence of iNPH increases with age: $0.2 \%$ at $70-79$ years and $5.9 \%$ at 80 years and older [5]. Tanaka et al. [6] considered a prevalence of iNPH in the elderly to be $1.4 \%$.

The designation $\mathrm{NPH}$ is subdivided into idiopathic $\mathrm{NPH}$ (iNPH) and secondary NPH (sNPH) [7], where sNPH arises as a possible consequence of meningitis, encephalitis, traumatic brain injury or subarachnoid hemorrhage [8]. A meticulous preoperative diagnosis is crucial for a favorable response to VP shunting in patients with iNPH [8]. Common comorbidities among iNPH patients, arterial hypertension, diabetes mellitus, and vascular dementia, may be major prognostic factors [9]. Neurodegenerative diseases (dementia with Lewy bodies, Parkinson`s disease, Alzheimer's disease, progressive supranuclear palsy, frontotemporal dementia) could also present with extrapyramidal symptoms mimicking some symptoms of NPH $[10,11]$. Therefore, a comprehensive differential testing is required. Imaging shows pathologically enlarged ventricular size with an Evans index [12] (the ratio of the widest diameter of the frontal horns to the widest diameter of the brain on the same axial slice) of more than $0.3[13,14]$. A corpus callosum angle of $40^{\circ}$ or more and a lack of subarachnoid space over the high convexity (DESH-disproportionately enlarged subarachnoid space hydrocephalus) are among the key neuroradiological features [8], together with a CSF opening pressure ranging from 5 to $18 \mathrm{mmHg}$ (or $70-245 \mathrm{mmH}_{2} \mathrm{O}$ ) [8]. Specific tests for iNPH include the lumbar infusion test, CSF drainage (tap test) by lumbar puncture or lumbar drain [15-21]. The results of the elaborate diagnostics correlate with the primary shunt response [21, 22].

The treatment of choice is ventriculoperitoneal (VP) shunt placement with adjustable valves [7] and about $74 \%$ of patients with iNPH benefit from VP shunting [22, 23]. Studies with long term follow up of iNPH patients after shunting suggest, that a number of patients show delayed deterioration of their symptoms despite an improvement in the first months [23, 24].

The aim of this study was to investigate iNPH patients from our register with secondary deterioration of their initially improved symptoms. The purpose was to find the number of patients with primary deterioration in the first year after VPS placement and also the number with primary improvement but followed by secondary worsening after VP shunting. Further, our goal was to determine clinical predictors for secondary worsening and to distinguish whether the deterioration is based on the progression of the hydrocephalus and/or co-morbidities, or associated with VP shunt malfunction. Based on our findings, we have also developed an algorithm for the standardization of treatment steps in order to further minimize the proportion of secondary non-responders.

\section{Materials and methods}

In our Department of Neurosurgery all patients with the suspected diagnosis iNPH were diagnosed using a published diagnostic pathway including an intrathecal infusion test and a CSF tap test [23]. A positive result in the invasive diagnostic method is defined as: (1) resistance to outflow $\left(R_{\text {out }}\right)$ of $13 \mathrm{mmHg} / \mathrm{min} \times \mathrm{mL}$ or more in the lumbar CSF infusion test; (2) improvement of the performance of walking and turning by a minimum of $20 \%$ after spinal tap test. If only one test turns out positive, then a lumbar drain is placed for 3 days to measure the performance of walking and turning over this period of time. In the case of a positive result in two diagnostic methods, the patient is classified for VP shunting. After VP shunting all patients are regularly scheduled for follow up examinations at 3, 6 and 12 months and thereafter yearly. During the follow up examinations we scored the patients' symptoms using the Kiefer score [25] (KS) for iNPH. The KS contains gait disorder (0-6 points), cognitive decline (0-6 points), urinary incontinence (0-6 points), headache (0-4 points), and vertigo (0-2 points). The symptoms were assigned according to their severity. Furthermore, we calculated the Evans indices from the recent cerebral computer tomographic (CT) scans at each follow-up. The comorbidity index (CMI) [26] describes the sum of the patients' comorbidities. Hypertension, aortofemoral bypass, stent, ICA stenosis, posterior circulation insufficiency, arrhythmia, valvular disease, heart failure, aortocoronary bypass and infarction are calculated with one point, respectively. Diabetes mellitus, peripheral vascular occlusion, vascular encephalopathy, transient ischemic attack, prolonged reversible neurologic deficit and Parkinson's disease are calculated by two points, respectively. The cerebral infarct is rated with three points. The collected data were entered in our iNPH registry file.

We retrospectively reviewed our iNPH registry. All patients in our registry underwent shunt surgery. Our iNPH registry was initiated in 1999 and is still ongoing. To determine the rate of iNPH patients with primary deterioration, we chose for review a period from 1999 until 2017. To investigate patients with secondary deterioration, we considered patients who were included in our registry until the end of 2013. This period allowed us to have enough follow-up time for analyzing the clinical course. Patients who showed equal or worse Kiefer scores in the first year of follow-up, compared to the preoperative score, were defined as "primary deteriorated". For this study, we did not investigate this subgroup in detail. 
"Secondary deterioration" was defined as a decrease by the minimum of two points in the Kiefer score in the first year of follow-up and an increase of two points in the Kiefer score between the second and the fifth year after shunt surgery. Patients with secondary deterioration resulting from a treatable mechanical shunt issue by decreasing the valve pressure setting, shuntography, and/ or surgical shunt revision were defined as "shunt insufficiency". Patients with secondary deterioration and unsuccessful shunt management (adapting the valve pressure setting, shuntography, valve replacement, catheter replacement, implantation of an adjustable gravitational unit) were assigned as "secondary non-responder".

All patients included in this study had received adjustable pressure valves with fixed gravitational valves (proGAV, Aesculap-Miethke, Potsdam, Germany; Medos-Hakim, Codman and Shurtleff, Johnson and Johnson, Ryanham, Massachusetts, USA). Patients with implanted DualSwitch valves (Aesculap-Miethke, Potsdam, Germany) were not considered in this investigation. The initial pressure level of the adjustable unit was set to 70-100 $\mathrm{mmH}_{2} \mathrm{O}$. At the 3 months follow-up, the valves were readjusted to $50-70 \mathrm{mmH}_{2} \mathrm{O}$. The decision to adjust the pressure was done because of several recommendations in literature suggesting better outcomes [27-29]. The decision for the pressure level of the fixed gravitational units was taken from the recommendation of the manufacturer $\left(200-300 \mathrm{mmH}_{2} \mathrm{O}\right)$.

In summary, the inclusion and exclusion criteria to the retrospective investigation of patients out of our iNPH registry were:

\section{Inclusion criteria}

- Patients with iNPH (typical symptoms, radiomorphological findings, infusion- test, spinal-tap-test).

- Implantation of adjustable units or non- adjustable gravitational units (pressure level $50-100 \mathrm{mmH}_{2} \mathrm{O}$ or 200-300 $\mathrm{mmH}_{2} \mathrm{O}$, respectively).

- Decrease of the Kiefer score by a minimum of 2 points in the first year after shunt surgery.

- Increase of the Kiefer score by a minimum of 2 points between the second and the fifth year after shunt surgery.

\section{Exclusion criteria}

- sNPH.

- Non-communicating hydrocephalus.

- Primary deterioration (pre-VP Shunting Kiefer score equal or better to Kiefer score in the first year of FU).

- Implanted shunt valves alone without shunt assistant.
In the second step, medical records of the included patients were screened. The medical management (adapting the valve pressure setting, shuntography, valve replacement, catheter replacement, implantation of an adjustable gravitational unit), performed to improve the symptoms of the patient, was evaluated. The medical records of the patients with secondary deterioration were screened for new diagnosed neurodegenerative diseases.

Statistical evaluation was performed using Prism for Mac OS (GraphPad) and Microsoft Excel for Windows (Microsoft Corp.). Differences between groups were tested using Chi-squared-test, Fisher's exact test, MannWhitney test, Kruskal-Willis test and the t-test. Multivariate analysis of variance was performed. The level of significance was defined as $\mathrm{p} \leq 0.05$.

\section{Results}

Between 1999 and 2017, 353 patients suffering from iNPH were surgically treated with VP Shunt in the Department of Neurosurgery of the Unfallkrankenhaus Berlin. Out of these 353 patients, 86 (24\% of 353) patients showed "primary deterioration". Eight patients $(2.2 \%$ of 353) were lost to follow-up in the first 6 months. In the period of 1999 until 2013, we included 259 patients in our iNPH registry. Fifty-three patients (20\% of 259) met our inclusion criteria (see Fig. 1). We observed secondary worsening on average 2.7 (2-4 years) years after shunt surgery. Out of this group, fourteen patients (26\% of 53) showed a manageable shunt insufficiency and improved according to the Kiefer score and thirty-one patients (59\% of 53) remained as secondary non-responders despite at least one action taken: decreasing the valve pressure setting, shuntography, valve replacement, catheter replacement, or implantation of an adjustable gravitational unit (Mann-Whitney $U$ test, $\mathrm{p}=0.004)$. Five $(16 \%)$ of the thirty-one patients developed radio-morphological and/ or clinical symptoms of overdrainage. Thus, the valve pressure had to be set to a higher opening pressure level (100-120 $\left.\mathrm{mmH}_{2} \mathrm{O}\right)$ with the consequence of increasing the Kiefer score.

Out of the group with "secondary deterioration" $(\mathrm{N}=53)$, we had a dropout rate of $15 \%$ (8 of 53 ) resulting from incomplete datasets for the follow up examinations. Although these eight patients showed secondary deterioration, the dataset of the follow-ups was not complete with regard to the medical management. We show the baseline data in Table 1 . There were no significant differences between the respective groups. Interestingly, the comorbidity index (CMI) [26] at the time of surgery was similar in all groups.

In Table 2, the respective accomplished medical management is depicted for patients with secondary deterioration. No statistically significant difference was found 


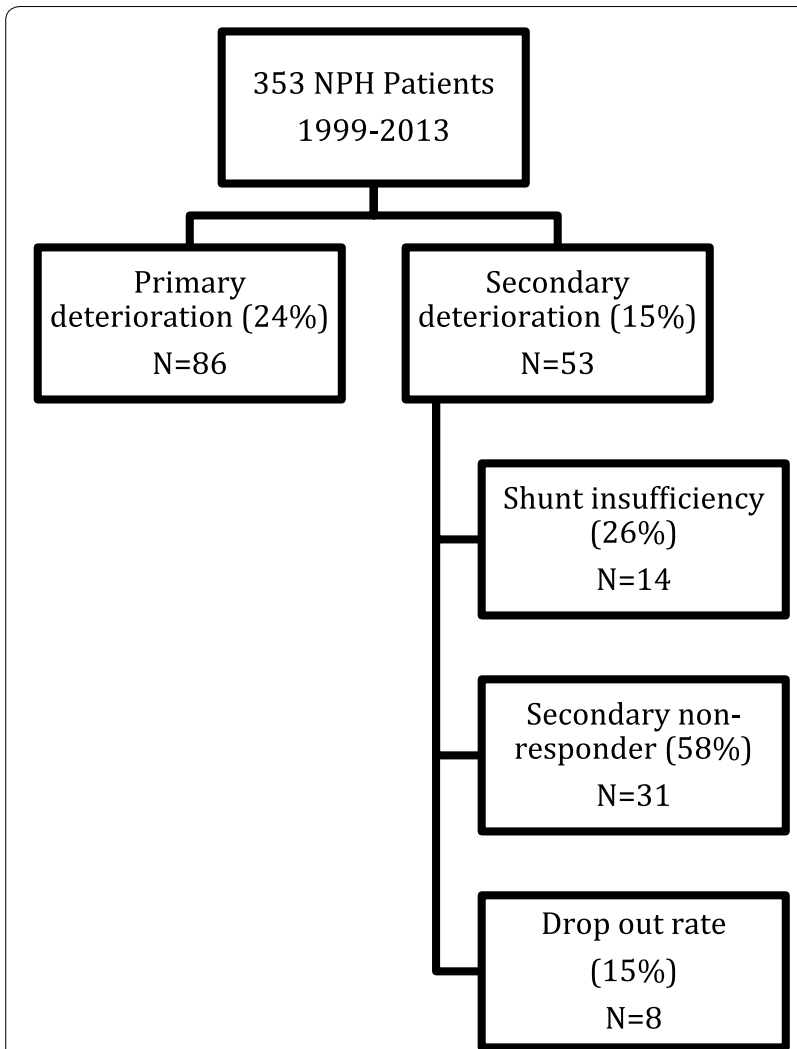

Fig. 1 Flow diagram showing our study population of normal pressure hydrocephalus patients (NPH)

between the two groups "shunt insufficiency" and "secondary non-responder".

The baseline data of the patients with "shunt insufficiency" and the "secondary non-responders" (see Table 3) showed that the "secondary non-responders" were older at time of surgery than the patients with "shuntinsufficiency" (73 vs. 68.5 years; t-test, $\mathrm{p}$-value $=0.01$ ). The preoperative CMI is equal in both investigated groups (Mann-Whitney test, $\mathrm{p}=\mathrm{ns}$ ) and similarly in the preoperative Kiefer score (Mann-Whitney test, $\mathrm{p}=0.10$ ). Patients with a newly diagnosed neurodegenerative disease after VP shunting are overrepresented, but not statistically significant, in the group of "secondary non-responders" (Fisher's exact test, $\mathrm{p}$-value $=\mathrm{ns}$ ). The presence of clinical and/or radio-morphological signs of overdrainage was noted exclusively in the subgroup of "secondary non-responder" (Fisher's exact test, p-value $=$ ns).

Following up our findings, we carried out a multivariate analysis of the risk factors. The multivariate analysis showed, that age is the strongest risk factor to become a "secondary non-responder" ( $\mathrm{p}$-value $=0.03$ ). The preoperative CMI and Kiefer score have no significant impact as a risk factor ( $\mathrm{p}$-value $=\mathrm{ns}$; $\mathrm{p}$-value $=\mathrm{ns}$ ). Overdrainage and newly diagnosed neurodegenerative diseases did not reach the significance level in the multivariate analysis ( $\mathrm{p}$-value $=$ ns; $\mathrm{p}$-value $=\mathrm{ns}$ ).

We compared the outcome of shunt management between the shunt insufficiency and the secondary nonresponder groups (Table 4). There was no statistically significant difference between the accomplished shunt management in these two groups. Although the results are not statistically significant, a more comprehensive shunt management (43\% in the "shunt insufficiency" group vs. $26 \%$ in the "secondary non-responder" group) seems to lead to a reversible secondary deterioration by completing all three shunt management steps. Thus, our

Table 1 Baseline demographic characteristics of the patients

\begin{tabular}{|c|c|c|c|c|c|c|c|c|}
\hline & $\begin{array}{l}\text { Total } \\
(1999-2017) \\
(\mathrm{N}=353)\end{array}$ & $\begin{array}{l}\text { Primary } \\
\text { deterioration } \\
(\mathrm{N}=86)\end{array}$ & $\begin{array}{l}\text { Total } \\
(1999-2013) \\
(\mathrm{N}=259)\end{array}$ & $\begin{array}{l}\text { Secondary } \\
\text { deterioration } \\
(\mathrm{N}=53)\end{array}$ & $\begin{array}{l}\text { Shunt } \\
\text { insufficiency } \\
(N=14)\end{array}$ & $\begin{array}{l}\text { Secondary } \\
\text { non-responder } \\
(\mathrm{N}=31)\end{array}$ & $\begin{array}{l}\text { Drop-outs } \\
(\mathrm{N}=8)\end{array}$ & Test and p-value \\
\hline \multicolumn{9}{|c|}{ Age (years) (at the time of surgery) } \\
\hline $\begin{array}{l}\text { Mean } \\
\quad(\text { median }) \pm S D\end{array}$ & $71.4(72) \pm 10$ & $74(72) \pm 10$ & $71(72) \pm 10$ & $70(72) \pm 11$ & $68.5(68) \pm 8$ & $73.3(72) \pm 4.2$ & $74.9(77) \pm 8.6$ & $\begin{array}{l}\text { Kruskal-Wallis test } \\
\mathrm{p}=\mathrm{ns}\end{array}$ \\
\hline \multicolumn{9}{|l|}{ Sex } \\
\hline Female n (\%) & $146(42 \%)$ & $40(47 \%)$ & $104(40 \%)$ & $22(41 \%)$ & $4(28 \%)$ & $15(48 \%)$ & $3(38 \%)$ & $\begin{array}{l}\text { Chi-square test } \\
p=n s\end{array}$ \\
\hline Male n (\%) & $207(58 \%)$ & $46(53 \%)$ & $155(60 \%)$ & $31(59 \%)$ & $10(72 \%)$ & $16(52 \%)$ & $5(62 \%)$ & \\
\hline \multicolumn{9}{|l|}{ Pre-VPS CMI } \\
\hline $\begin{array}{l}\text { Mean } \\
\quad(\text { median }) \pm S D\end{array}$ & $2.6(3) \pm 1.9$ & $2.2(2) \pm 1.9$ & $2.7(3) \pm 2$ & $2.5(2) \pm 2$ & $2.2(3) \pm 1.8$ & $2.7(2) \pm 2.3$ & $2.1(1.5) \pm 2.1$ & $\begin{array}{l}\text { Kruskal-Wallis test } \\
\mathrm{p}=\mathrm{ns}\end{array}$ \\
\hline \multicolumn{9}{|l|}{ Kiefer score } \\
\hline $\begin{array}{l}\text { Mean } \\
\quad(\text { median }) \pm S D\end{array}$ & $7.1(7) \pm 2.9$ & $6.1(6) \pm 2.7$ & $7.6(7) \pm 3$ & $6.8(7) \pm 2.7$ & $7(7) \pm 3.6$ & $6.8(7) \pm 2.3$ & $6.9(6.5) \pm 2.2$ & $\begin{array}{l}\text { Kruskal-Wallis test } \\
\mathrm{p}=\mathrm{ns}\end{array}$ \\
\hline
\end{tabular}


Table 2 Shunt management of the patients with secondary deterioration with the exclusion of the patients with overdrainage

\begin{tabular}{llrl}
\hline & Shunt insufficiency $(\mathbf{N}=\mathbf{1 4})$ & Secondary non-responder $(\mathbf{N}=\mathbf{2 6})$ & Test and $\mathbf{p}$-value \\
\hline Valve pressure $\left(0-30 \mathrm{mmH}_{2} \mathrm{O}\right)(\mathrm{N})$ & 14 & 26 & $\begin{array}{l}\text { Fisher's exact test } \\
\mathrm{p}=\mathrm{ns}\end{array}$ \\
Shuntography $(\mathrm{N})$ & 8 & 14 & $\begin{array}{l}\text { Fisher's exact test } \\
\mathrm{p}=\mathrm{ns}\end{array}$ \\
Implantation of an adjustable ASD $(\mathrm{N})$ & 6 & 7 & $\begin{array}{l}\text { Fisher's exact test } \\
\text { Catheter replacement }(\mathrm{N})\end{array}$ \\
\hline
\end{tabular}

$A S D$ anti-siphon-device

Table 3 Comparison of the two patient groups

\begin{tabular}{|c|c|c|c|}
\hline & Shunt insufficiency $(\mathrm{N}=14)$ & $\begin{array}{l}\text { Secondary non-responder } \\
(\mathrm{N}=31)\end{array}$ & Test and p-value \\
\hline \multicolumn{4}{|l|}{ Age } \\
\hline Mean (median) $\pm S D$ (at the time of surgery) & $68.5(68) \pm 8$ & $73.3(72) \pm 4.2$ & $\begin{array}{l}\text { t-test } \\
p=0.01\end{array}$ \\
\hline \multicolumn{4}{|l|}{ Pre-VPS CMI } \\
\hline Mean (median) $\pm S D$ & $2.2(3) \pm 1.8$ & $27(2) \pm 2.3$ & $\begin{array}{l}\text { Mann-Whitney test } \\
\mathrm{p}=\mathrm{ns}\end{array}$ \\
\hline \multicolumn{4}{|l|}{ Kiefer score } \\
\hline Mean (median) \pm SD & $7(7) \pm 3.6$ & $6.8(7) \pm 2.3$ & $\begin{array}{l}\text { Mann-Whitney test } \\
\mathrm{p}=\mathrm{ns}\end{array}$ \\
\hline $\begin{array}{l}\text { New diseases during the F/U (stroke, Alzheimer disease, } \\
\text { Parkinson disease) }\end{array}$ & $1(7 \%)$ & $6(19 \%)$ & $\begin{array}{l}\text { Fisher's exact test } \\
p=n s\end{array}$ \\
\hline $\begin{array}{l}\text { Over-drainage requiring valve pressure set- } \\
\text { ting } \geq 100 \mathrm{mmH}_{2} \mathrm{O}\end{array}$ & $0(0 \%)$ & $5(16 \%)$ & $\begin{array}{l}\text { Fisher's exact test } \\
\mathrm{p}=\mathrm{ns}\end{array}$ \\
\hline
\end{tabular}

CMI Comorbidity Index, VPS ventriculoperitoneal shunt, F/U follow-up

Table 4 Comparison of the shunt management as measured by improvement in the Kiefer score, of the shuntinsufficiency group and the group of secondary non-responders, after exclusion of the patients with overdrainage

\begin{tabular}{|c|c|c|c|}
\hline & Shunt insufficiency ( $N=14)$ & $\begin{array}{l}\text { Secondary non-responder } \\
(\mathrm{N}=26)\end{array}$ & Test and $p$-value \\
\hline Valve pressure setting $(\mathrm{N})$ & $5(36 \%)$ & $12(46 \%)$ & $\begin{array}{l}\text { Fisher's exact test } \\
\mathrm{p}=\mathrm{ns}\end{array}$ \\
\hline Valve pressure setting + shuntography $(\mathrm{N})$ & $3(21 \%)$ & $7(27 \%)$ & $\begin{array}{l}\text { Fisher's exact test } \\
\mathrm{p}=\mathrm{ns}\end{array}$ \\
\hline $\begin{array}{l}\text { Valve pressure setting + shuntography + implantation of } \\
\text { an adjustable ASD (N) }\end{array}$ & $6(43 \%)$ & $7(27 \%)$ & $\begin{array}{l}\text { Fisher's exact test } \\
\mathrm{p}=\mathrm{ns}\end{array}$ \\
\hline
\end{tabular}

ASD anti-siphon-device

shunt-management decreased the rate of secondary deterioration in the total investigated study population from 20 to $15 \%$ (Fisher's exact test, $\mathrm{p}=\mathrm{ns}$ ).

Based on our results that comprehensive shunt management seems to show the opportunity for optimize the long-term outcome of iNPH patients. Over 64\% (see Table 4) of the patients in "shunt insufficiency" group needed invasive shunt management with at least shuntography and finally the replacement of the fixed antisiphon device (ASD) to an adjustable device to improve the symptoms. In the group of "secondary nonresponder", $54 \%$ got invasive shunt management.

Therefore, we developed an algorithm of a complex treatment strategy of iNPH patients with deterioration 
after VPS placement with the purpose to decrease the rate of "secondary non-responder". Figure 2 shows in detail our steps of management of these patients.

\section{Discussion}

Our results reveal that $20 \%$ of the iNPH patients treated with VP shunting (VPS) deteriorated in their symptoms after an average of 2.7 years, despite a clinical benefit in the first year after the VPS. The observation, that a delayed deterioration occurred at an average of more than 2 years after VPS, is consistent with published studies $[11,30]$. Twenty-six percent of the patients with secondary deterioration improved after shunt/valve management, $59 \%$ remained without clinical benefit after taking action of the VPS. The results of the "shunt insufficiency" group shows, that over $64 \%$ of the patients require a more complex therapy strategy than adjustment of the pressure level of the valve. Patients of the "secondary nonresponder" group completed in only $27 \%$ all three steps of shunt management. We were able to reduce the rate of secondary deterioration from 20 to $15 \%$ with our shunt management. This leads to an improvement in the longterm outcome of iNPH patients. However, it cannot be ruled out that more consistent use of our proposed algorithm could further minimize the non-responder rate.

\section{Shunt management}

Kahlon et al. [24] showed in the long-term follow-up study of patients with clinical symptoms of NPH, that only $20 \%$ of these patients continued clinical improvement after 5 years. A criticism of the study would be that not all patients completed the long term follow up because of a high mortality rate of $37 \%$. Moreover, it is not mentioned whether shunt revision were performed to improve the symptoms [24].

Toma et al. [30] reviewed 64 studies with 3063 patients concerning the outcome of shunt surgery in patients with
$\mathrm{NPH}$. The author concluded that the benefit of VPS is long lasting, but requires frequent shunt revisions. Pujari et al. [31] revealed, that over $80 \%$ of his patients showed an improvement in the follow up examination after 7 years and $53 \%$ required multiple shunt revisions. Other studies reported a shunt failure rate up to $32 \%$ [32, 33]. However, Reddy et al. [33] noticed, that the majority of the shunt revisions occur in the first 6 months after VPshunting. Regarding our results, a surgical shunt revision is not necessary in all cases of secondary deterioration to improve the symptoms. Adjusting the valve pressure level or shuntography may be sufficient. In cases where neither results in the desired therapeutic effect we recommend to replace the fixed ASD with an adjustable ASD (see Fig. 2). Kehler et al. [34] verified in a prospective registry study, that the implantation of an adjustable ASD (proSA) adds no further risk and results in improvement of the hydrocephalus symptoms in 55\% of the patients. Furthermore, the author added, that the proSA gives the opportunity for several adjustments in order to find the appropriate setting for the patient [34]. This suggests adjustable gravitational units should be implanted at the time of the first surgery. Before the start of recruitment in the SYGRAVA [35] trial, we did not implant adjustable gravitational units in the first surgery due to missing prospective trial data. This prospective trial is being conducted on the subject of efficiency and safety of adjustable gravitational units [35].

\section{Risk factors}

Another focus of our study was to determine risk factors for the development of "secondary non-responder". The "secondary non-responder "group was significantly older than the "shunt insufficiency" group (68 years vs. 73 years). Kahlon et al. [24] investigated in the long-term evaluation of patients with NPH and VPS, found that $64 \%$ of the younger patients (mean 66.7 years) continued to

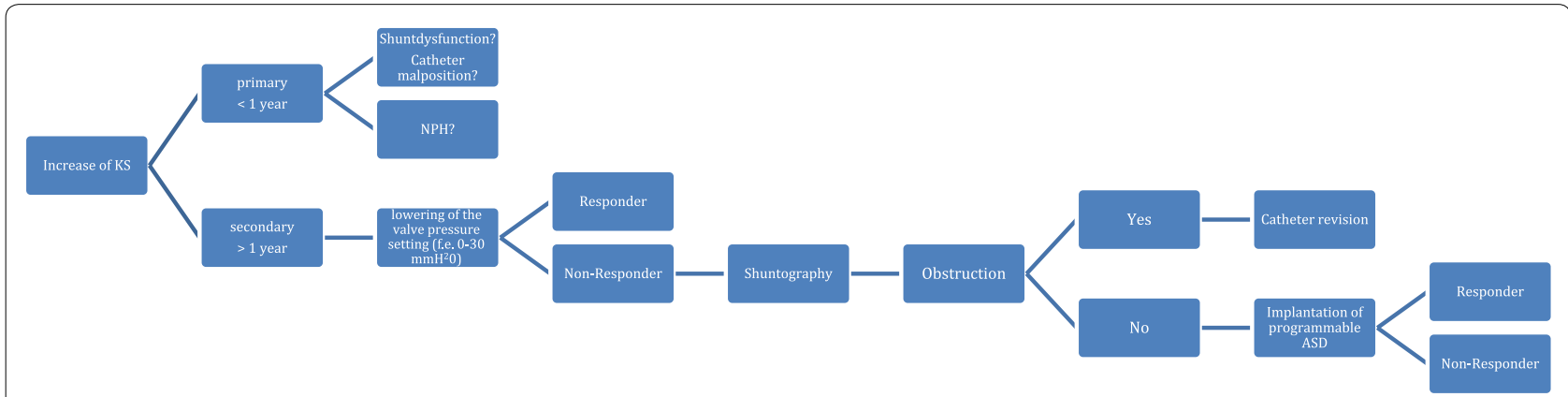

Fig. 2 Algorithm for shunt management of patients with normal pressure hydrocephalus and ventriculoperitoneal shunt. Based on our findings, in 2018, we developed and established in our department this algorithm for management of normal pressure hydrocephalus patients to decrease the rate of "secondary non- responder". KS Kiefer score, NPH normal pressure hydrocephalus 
show improvement in the walk tests, with only $11 \%$ of the older patients (mean 74.7 years) continuing to improve [24].

It can be assumed that the patient's age increases the likelihood that further neurodegenerative diseases (Alzheimer's disease, dementia with Lewy bodies, Parkinson disease, progressive supranuclear palsy) may occur. As in our study, neurodegenerative diseases are frequent causes of poor outcome after VP-shunting [22]. The extrapyramidal symptoms of these diseases can mimic the symptoms of patients with NPH [36]. Even these patients can improve temporarily after VP-shunting [10]. It cannot be excluded, that some of our shunted patients were in the preclinical phase of the neurodegenerative disease at the time of surgery. Thus, it is essential to rule out meticulously the disease before VPS placement. Junkkari et al. [37] highlighted in the recently published study, that an accurate identification of NPH has a huge impact on the results of our treatment. Consequently, a systemic diagnostic workup becomes indispensable [37]. Espay et al. [38] goes one step further and postulates that the NPH should be a diagnosis of exclusion that requires careful consideration of neurodegenerative disorders [38]. But he also concluded in the study, that VP-shunting may remain a reasonable option for short-term management of patients with neurodegenerative disorders [38]. Junkkari et al. [37] points out that additional tests should not delay treatment.

A further significant risk factor in our study seems to be clinical and radio-morphological signs of overdrainage. Overdrainage only occurred in the group of "secondary non-responders". This could be explained by bias in the definition of both groups, which consequently places the classification of these patients in favor of the group with "secondary non-responder". The therapeutic aim with overdrainage is to reduce the CSF flow rates in the VPS by adjusting the valve setting to higher pressure levels. In our department we first increase the opening pressure setting to a minimum of $100 \mathrm{mmH}_{2} \mathrm{O}$. Alternatively, we replace the fixed gravitational unit with an adjustable gravitational unit.

\section{Limitations}

In our Department all patients with the suspected iNPH were diagnosed following a standardized diagnostic pathway including intrathecal infusion test and CSF tap test. Nevertheless, this pathway may not be able to completely exclude patients with other neurodegenerative disorders mimicking NPH symptoms. Unfortunately, new neurological diseases were screened out of the medical records available in our hospital and external medical records are usually not accessible in the case of treatment outside of our hospital. As this is a retrospective study, it cannot be ruled out that, over such a long period (1999 to 2013), clinical decisions that could influence the results have changed. Our proposed algorithm for shunt management is based on one center results without prospective randomized evaluation and was developed for standardization of therapeutic decisions in the event of secondary deterioration. Therefore, we cannot exclude that the group of "secondary non-responder" included some patients with "shunt insufficiency". The next aim is to evaluate our algorithm in prospective manner in order to have statistical validity. The quality of evidence of the algorithm corresponds to level III. Furthermore, given the dropout rate of $15 \%$, it cannot be excluded that these patients could no longer complete follow-up due to clinical worsening.

\section{Conclusion}

Twenty percent of a large cohort of patients who initially benefitted from VPS for iNPH developed "secondary deterioration" 2.7 years after surgery. Due to several actions of shunt management following an algorithm, about one quarter of these patients recovered the initial benefits.

Higher age at the time of shunting, newly diagnosed neurodegenerative diseases, and overdrainage requiring adjusting the valve to higher pressure levels might be risk factors for becoming "secondary non-responder". These findings underline the importance of long-term followups and lifelong care to achieve favorable outcomes for patients with iNPH. In the case of secondary deterioration, a complex therapy management including invasive methods should be considered.

\section{Abbreviations}

iNPH: Idiopathic normal pressure hydrocephalus; NPH: Normal pressure hydrocephalus; sNPH: Secondary normal pressure hydrocephalus; VPS: Ventriculoperitoneal shunt; CSF: Cerebrospinal fluid; KS: Kiefer score; CCT: Cerebral computer tomography; ASD: Anti-siphon device; F/U: Follow-up; CMI: Comorbidity index.

\section{Acknowledgements \\ Not applicable.}

\section{Authors' contributions}

PG and SR analyzed and interpreted equally the datasets. PG was the main contributor in writing the manuscript. LG interpreted the CT scans. MF proposed to work on the topic of secondary non-responder. All authors read and approved the final manuscript.

\section{Funding \\ No funding was received for this research.}

\section{Availability of data and materials}

The datasets used during the current study are available from the corresponding author on reasonable request.

\section{Ethical approval and consent to participate}

All procedures performed in studies involving human participants were in accordance with the ethical standards of the institutional and committee and 
with the 1964 Helsinki declaration and its later amendments or comparable ethical standards. For this type of study formal consent is not required.

\section{Competing interests}

All authors certify that they have no affiliations with or involvement in any organization or entity with any financial interest (such as honoraria; educational grants; participation in speakers' bureaus; membership, employment, consultancies, stock ownership, or other equity interest; and expert testimony or patent-licensing arrangements), or non-financial interest (such as personal or professional relationships, affiliations, knowledge or beliefs) in the subject matter or materials discussed in this manuscript.

\section{Author details}

${ }^{1}$ Department of Neurosurgery, Unfallkrankenhaus Berlin, Warener Straße 7, 12683 Berlin, Germany. ${ }^{2}$ Department of Neurosurgery, Dietrich Bonhoeffer Klinikum, Neubrandenburg, Germany. ${ }^{3}$ Department of Radiology and Neuroradiology, Unfallkrankenhaus Berlin, Berlin, Germany.

Received: 27 September 2019 Accepted: 24 February 2020

Published online: 04 March 2020

\section{References}

1. Adams RD, Fischer CM, Hakim S, Ojemann RG, Sweet WH. Symptomatic occult hydrocephalus with normal cerebrospinal-fluid pressure-a treatable syndrome. N Engl J Med. 1965. https://doi.org/10.1056/NEJM196507 152730301.

2. Lemcke J, Stengel D, Stockhammer F, Güthoff C, Rohde V, Meier U. Nationwide incidence of normal pressure hydrocephalus (NPH) assessed by insurance claim data in Germany. Open Neurol J. 2016;10(1):15-24. https://doi.org/10.2174/1874205x01610010015.

3. Klassen BT, Ahlskog JE. Normal pressure hydrocephalus: how often does the diagnosis hold water? Neurology. 2011;77(12):1119-25. https://doi. org/10.1212/WNL.0b013e31822f02f5.

4. Brean A, Fredø HL, Sollid S, Müller T, Sundstrøm T, Eide PK. Five-year incidence of surgery for idiopathic normal pressure hydrocephalus in Norway. Acta Neurol Scand. 2009;120(5):314-6. https://doi.org/10.111 1/j.1600-0404.2009.01250.x.

5. Jaraj D, Rabiei K, Marlow T, Jensen C, Skoog I, Wikkelsø C. Prevalence of idiopathic normal-pressure hydrocephalus. Neurology. 2014;82(16):144954. https://doi.org/10.1212/WNL.0000000000000342.

6. Tanaka N, Yamaguchi S, Ishikawa H, Ishii H, Meguro K. Prevalence of possible idiopathic normal-pressure hydrocephalus in Japan: the Osaki-Tajiri project. Neuroepidemiology. 2009;32(3):171-5. https://doi. org/10.1159/000186501.

7. Halperin JJ, Kurlan R, Schwalb JM, Cusimano MD, Gronseth G, Gloss D. Practice guideline: idiopathic normal pressure hydrocephalus: response to shunting and predictors of response. Neurology. 2015;85(23):2063-71. https://doi.org/10.1212/wnl.0000000000002193.

8. Williams MA, Relkin NR. Diagnosis and management of idiopathic normal-pressure hydrocephalus. Neurol Clin Pract. 2013;3(5):375-85. https://doi.org/10.1212/CPJ.0b013e3182a78f6b.

9. Malm J, Graff-Radford NR, Ishikawa M, et al. Influence of comorbidities in idiopathic normal pressure hydrocephalus-research and clinical care. A report of the ISHCSF task force on comorbidities in INPH. Fluids Barriers CNS. 2013;10(1):1. https://doi.org/10.1186/2045-8118-10-22.

10. Korhonen VE, Solje E, Suhonen NM, et al. Frontotemporal dementia as a comorbidity to idiopathic normal pressure hydrocephalus (iNPH): a short review of literature and an unusual case. Fluids Barriers CNS. 2017;14(1):15. https://doi.org/10.1186/s12987-017-0060-7.

11. Benveniste RJ, Sur S. Delayed symptom progression after ventriculoperitoneal shunt placement for normal pressure hydrocephalus. J Neurol Sci. 2018;393(July):105-9. https://doi.org/10.1016/j.jns.2018.08.002.

12. Evans WA. An encephalographic ratio for estimating ventricular enlargement and cerebral atrophy. Arch Neurol Psychiatry. 1942. https://doi. org/10.1001/archneurpsyc. 1942.02290060069004.

13. Hakim S, Adams RD. The special clinical problem of symptomatic hydrocephalus with normal cerebrospinal fluid pressure. Observations on cerebrospinal fluid hydrodynamics. J Neurol Sci. 1965;273(3):117-26. https://doi.org/10.1016/0022-510x(65)90016-x.
14. Ambarki K, Israelsson H, Wåhlin A, Birgander R, Eklund A, Malm J. Brain ventricular size in healthy elderly: comparison between Evans index and volume measurement. Neurosurgery. 2010. https://doi.org/10.1227/01. NEU.0000370939.30003.D1.

15. El Ahmadieh TY, Wu EM, Kafka B, et al. Lumbar drain trial outcomes of normal pressure hydrocephalus: a single-center experience of 254 patients. J Neurosurg. 2019. https://doi.org/10.3171/2018.8.jns181059.

16. Wikkelso C, Andersson H, Blomstrand C, Lindqvist G. The clinical effect of lumbar puncture in normal pressure hydrocephalus. J Neurol Neurosurg Psychiatry. 1982. https://doi.org/10.1136/jnnp.45.1.64.

17. Haan J, Thomeer RTWM. Predictive value of temporary external lumbar drainage in normal pressure hydrocephalus. Neurosurgery. 1988. https:// doi.org/10.1227/00006123-198802000-00020.

18. Sand T, Bovim G, Grimse R, Myhr G, Helde G, Cappelen J. Idiopathic normal pressure hydrocephalus: the CSF tap-test may predict the clinical response to shunting. Acta Neurol Scand. 1994. https://doi. org/10.1111/j.1600-0404.1994.tb02640.x.

19. Marmarou A, Young HF, Aygok GA, et al. Diagnosis and management of idiopathic normal-pressure hydrocephalus: a prospective study in 151 patients. J Neurosurg. 2005;102(6):987-97. https://doi.org/10.3171/ jns.2005.102.6.0987.

20. Eklund A, Smielewski P, Chambers I, et al. Assessment of cerebrospinal fluid outflow resistance. Med Biol Eng Comput. 2007;45(8):719-35. https ://doi.org/10.1007/s11517-007-0199-5.

21. Skalický P, Mládek A, Vlasák A, De Lacy P, Beneš V, Bradáč O. Normal pressure hydrocephalus - an overview of pathophysiological mechanisms and diagnostic procedures. Neurosurg Rev. 2019. https://doi.org/10.1007/ s10143-019-01201-5.

22. Savolainen S, Hurskainen H, Paljärvi L, Alafuzoff I, Vapalahti M. Five-year outcome of normal pressure hydrocephalus with or without a shunt: predictive value of the clinical signs, neuropsychological evaluation and infusion test. Acta Neurochir. 2002;144(6):515-23. https://doi.org/10.1007/ s00701-002-0936-3.

23. Gölz L, Ruppert F-H, Meier U, Lemcke J. Outcome of modern shunt therapy in patients with idiopathic normal pressure hydrocephalus 6 years postoperatively. J Neurosurg. 2014;121(4):771-5. https://doi. org/10.3171/2014.6.jns131211.

24. Kahlon B, Sjunnesson J, Rehncrona S. Long-term outcome in patients with suspected normal pressure hydrocephalus. Neurosurgery. 2007;60(2):327-32. https://doi.org/10.1227/01.NEU.0000249273.41569.6E.

25. Kiefer M, Eymann R, Komenda Y, Steudel WI. Ein Graduierungssystem für den chronischen Hydrozephalus. Zentralbl Neurochir. 2003;64(3):109-15. https://doi.org/10.1055/s-2003-41881.

26. Kiefer M, Eymann R, Steudel WI. Outcome predictors for normal-pressure hydrocephalus. Acta Neurochir Suppl. 2006;96:364-7. https://doi. org/10.1007/3-211-30714-1_75.

27. Boon AJ, Tans JT, Delwel EJ, Egeler-Peerdeman SM, Hanlo PW, Wurzer HA, Avezaat CJ, de Jong DA, Gooskens RH, Hermans J. Normal-pressure hydrocephalus study: randomized comparison of low- and mediumpressure shunts. J Neurosurg. 1998;88:490-5.

28. Delwel EJ, De Jong DA, Dammers R, Kurt E, Van Den Brink W, Dirven CMF. A randomised trial of high and low pressure level settings on an adjustable ventriculoperitoneal shunt valve for idiopathic normal pressure hydrocephalus: results of the Dutch evaluation programme Strata shunt (DEPSS) trial. J Neurol Neurosurg Psychiatry. 2013;84(7):813-7. https://doi. org/10.1136/jnnp-2012-302935.

29. Lemcke J, Meier U, Müller C, et al. Safety and efficacy of gravitational shunt valves in patients with idiopathic normal pressure hydrocephalus: a pragmatic, randomised, open label, multicentre trial (SVASONA). J Neurol Neurosurg Psychiatry. 2013;84(8):850-7. https://doi.org/10.1136/jnnp2012-303936.

30. Toma AK, Papadopoulos MC, Stapleton S, Kitchen ND, Watkins LD. Systematic review of the outcome of shunt surgery in idiopathic normalpressure hydrocephalus. Acta Neurochir. 2013;155(10):1977-80. https:// doi.org/10.1007/s00701-013-1835-5.

31. Pujari S, Kharkar S, Metellus P, Shuck J, Williams MA, Rigamonti D. Normal pressure hydrocephalus: long-term outcome after shunt surgery. J Neurol Neurosurg Psychiatry. 2008;79(11):1282-6. https://doi.org/10.1136/ jnnp.2007.123620. 
32. Nigim F, Critchlow JF, Schneider BE, Chen C, Kasper EM. Shunting for hydrocephalus: analysis of techniques and failure patterns. J Surg Res. 2014;191(1):140-7. https://doi.org/10.1016/j.jss.2014.03.075.

33. Reddy GK, Bollam P, Caldito G. Long-term outcomes of ventriculoperitoneal shunt surgery in patients with hydrocephalus. World Neurosurg. 2014;81(2):404-10. https://doi.org/10.1016/j.wneu.2013.01.096.

34. Kehler U, Kiefer M, Eymann R, et al. PROSAIKA: a prospective multicenter registry with the first programmable gravitational device for hydrocephalus shunting. Clin Neurol Neurosurg. 2015;137:132-6. https://doi. org/10.1016/j.clineuro.2015.07.002.

35. Scholz R, Lemcke J, Meier U, Stengel D. Efficacy and safety of programmable compared with fixed anti-siphon devices for treating idiopathic normal-pressure hydrocephalus (iNPH) in adults_-SYGRAVA: study protocol for a randomized trial 11 Medical and Health Sciences 1103 Clinical Sciences. Trials. 2018;19(1):1-10. https://doi.org/10.1186/s1306 3-018-2951-6.
36. Starr BW, Hagen MC, Espay AJ. Hydrocephalic parkinsonism: lessons from normal pressure hydrocephalus mimics. J Clin Mov Disord. 2014;1 (1):2. https://doi.org/10.1186/2054-7072-1-2.

37. Junkkari A, Luikku AJ, Danner N, et al. The Kuopio idiopathic normal pressure hydrocephalus protocol: initial outcome of 175 patients. Fluids Barriers CNS. 2019;16(1):1-12. https://doi.org/10.1186/s12987-019-0142-9.

38. Espay AJ, Da Prat GA, Dwivedi AK, et al. Deconstructing normal pressure hydrocephalus: ventriculomegaly as early sign of neurodegeneration. Ann Neurol. 2017;82(4):503-13. https://doi.org/10.1002/ana.25046.

\section{Publisher's Note}

Springer Nature remains neutral with regard to jurisdictional claims in published maps and institutional affiliations.
Ready to submit your research? Choose BMC and benefit from:

- fast, convenient online submission

- thorough peer review by experienced researchers in your field

- rapid publication on acceptance

- support for research data, including large and complex data types

- gold Open Access which fosters wider collaboration and increased citations

- maximum visibility for your research: over $100 \mathrm{M}$ website views per year

At BMC, research is always in progress.

Learn more biomedcentral.com/submissions 